\title{
Exploring the Perception on Humanitarian Issues from the Health Science Students of Indian and Malaysian Nationality: A Cross Sectional Study
}

\author{
Naveen Kumar ${ }^{1}$, Nur Amni Binti Mohd Shamsuddin ${ }^{2}$, Noramylia Binti Jamil ${ }^{2}$, Atiqah Binti \\ Mohd Zayed ${ }^{2}$, Swamy Ravindra $S^{1}$, Anitha Guru ${ }^{1}$, Jyothsna Patil ${ }^{1}$, Ashwini Aithal P $^{1}$ \\ ${ }^{1}$ Department of Anatomy, ${ }^{2}$ Medical Student, Melaka Manipal Medical College (Manipal campus), Manipal \\ University, Manipal, India.
}

ARTICLE INFO

Received : : $18 / 10 / 2014$

Accepted : :23/03/2015

Published $\quad: 10 / 06 / 2015$

\section{KEYWORD}

Humanitarian

Malaysian

Indian

Student perception

Awareness

\section{ABSTRACT}

Objective: The idea of humanitarianism is evolving with progressing life. Awareness about this global issue has to be emphasized particularly among the younger generation and thus be encouraged to be exposed and involved in humanitarian projects in need. Being responsible citizens of the country one should develop concern about the humanitarian issues, and this attitude needs to be developed from student life. Methods: A cross sectional survey was conducted on 200 participants of the Malaysian and Indian (100 each) health science students using faculty validated close ended questionnaire. Results of the data were analyzed statistically by testing with chi square analysis from SPSS software. Results: From the present study, it has been observed that, despite the cultural and economical diversity between the two nations, there was no observable difference in student's point of view on humanitarian issues in most of the areas concerned. Overall evaluation also reflected effect of the socio-economic status of the countries on the perception of the issue amongst the students. Conclusion: Despite of different geography, diverse culture and dissimilar socio-economic status, the need of concern towards humanitarian issues is observable. Students of both nations have positive attitude towards the humanitarian issues as well.

(c) Medical Education Department, School of Medical Sciences, Universiti Sains Malaysia. All rights reserved.

CORRESPONDING AUTHOR: Dr. Swamy Ravindra S, Department of Anatomy, Melaka Manipal Medical College (Manipal campus), Manipal University, Manipal- 576104, Karnataka state, India.

Email: ravindrammmc@gmail.com

\section{Introduction}

Humanitarians assist is an event or situation which forms a provision of aid towards widespread human suffering. It is the oil that greases the step toward achieving world peace. There should not be any biased action in the face of suffering or abused on grounds of gender, sexual orientation, tribe, caste, age, religion or nationality. With all the war, poverty and discrimination happening all around the world, many people in a number of countries had a crisis of conscience and found that they could no longer tolerate or look away while men are killed, women are raped and abused. Almost every day we are bombarded with news on lack of humanity around the world.

Humanitarian community responds to violence during wars or when world falls victim to natural disasters which requires timely help. Such help sees no borders. Health care workers play vital 
role in this aspect, provided they have intense awareness of the issue in order to tackle and respond appropriately (1). Intricate emergencies basically involve numerous refugees. Fortunately, many organizations have been established to fight for the victim. However each crisis scenario comes with a set of unique problems with a common need that require correct measure at right time (2).

Most rehabilitative care for victims is established by well-organized public health services. Better health care is one of the most important and desired by the people. Health science professionals are needed to be aware about the humanitarian issues and correct measures during their school life itself.

The volunteered skills of physicians can be a tremendous resource for any community in need. Number of organizations relies heavily on large numbers of medical and paramedical volunteer efforts such as the American Red Cross, many rural Emergency Medical Service (EMS) squads, fire departments and 'Reach Out' which is a volunteer network of physicians (3).

Having said this, the present study has been devised to direct our research on health science student's perception towards humanitarian issues and compare this perception between two populations hailing from two geographically distinct nationalities of the Asian continent that is India and Malaysia. This research investigated the knowledge, awareness and preferred action towards humanitarian by the undergraduate students of Indian and Malaysian origin. The factors affecting student's attitude towards the issue have been emphasized as a reflection of their opinion expressed in the current survey based study.

\section{Method}

\section{Study material and Study group}

Faculty validated close ended questionnaire was designed and distributed to Malaysian and Indian undergraduate health science students. Relevant ethical approval was obtained from the
Institutional Research Committee before conducting this study.

\section{Study sample size}

Total number of students participated in the current study was 200 (100 each students from citizens of Malaysian and Indian). Selection of subjects was random with the prior confirmation of nationality.

\section{Data Analysis}

The data obtained by the responses of the participants were scrutinized carefully and compiled results of data were analyzed statistically using SPSS version 16.0. The independent- $t$ test was applied to test the significant difference between various student perspectives on humanitarian issues between two nations wherever applicable. Minimum level of significance ( $p$ value) was set to be less than 0.05 .

\section{Result}

Upon data evaluation and their statistical analysis, tested parameters measuring perception of health science students towards the humanitarian issue revealed following facts.

\section{Residential location of the participants:}

Awareness on humanitarian issues among the students might have been affected as residential location of the individual differs. In the current survey study, $82 \%$ of Malaysian and $54 \%$ of Indian student participants were found to be residing in urban area, while rest of the participants were from rural area. This differences with respect to two nations was statistically significant $(\mathrm{p}<0001)$.

2. Environmental factors: Similar to residential location, environmental factors could also play vital role in the attitude towards humanitarian perspective. It has been reflected in the present study that $11 \%$ of Malaysian and $12 \%$ of Indian students admitted that, they hail from the environment where discriminative factors are practiced. This narrow range of difference was statistically insignificant $(\mathrm{p}=0.825)$. 


\section{Student's concern towards humanitarian} issues: Questionnaire on students concern towards humanitarian issues revealed no significant differences in the concern among the Malaysian (92\%) and Indian (91\%) student population $(\mathrm{p}=0.832)$.

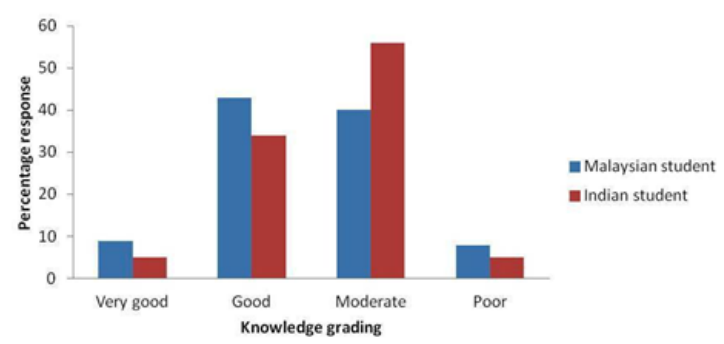

Figure 1: Grading pattern of different knowledge levels rated by Malaysian and Indian students

4. Role of family and attitude of best friends: To develop a concern towards humanitarian issues from the students, role of family members and attitude of their best friends are highly appreciated. Fortunately, in majority of the responses, family members ( $71 \%$ of Malaysian and $86 \%$ of Indian) were found to be encouraging their children. But the difference observed by the responses between 2 groups showed statistically significant $(\mathrm{p}=0.010)$. On the other hand, majority of participant's best friends ( $82 \%$ of Malaysian and $77 \%$ of Indian students) were also in favor of positive attitudes. However, this difference between 2 groups was observed to be statistically insignificant $(\mathrm{p}=0.064)$.

5. Student's interest profile: Test on student's interest in any of the humanitarian issues showed a predominant response in agreement expressing their interest between Malaysian $(85 \%)$ and Indian $(72 \%)$ student population. Nevertheless, the difference of interest between two population was found to be statistically significant $(\mathrm{p}=0.025)$.

6. Necessity of concern: An opinion among the students of two nations noted a favor for necessity of concern with the humanitarianism related issues. $94 \%$ of Malaysian and $85 \%$ of Indian students agree with the necessity of concern with the issue and statistically significant difference $(\mathrm{p}=0.03)$ of opinions was established through this survey.
7. Knowledge about the issue: The comparison test on knowledge about the humanitarian issue revealed higher percentage $(43 \%)$ good knowledge among Malaysian students and moderate $(56 \%)$ knowledge in Indian students (Figure 1). This differences in the knowledge were statistically insignificant $(\mathrm{p}=0.135)$.

8. Accessibility towards the issue: An accessibility perspective test showed good accessibility for the majority (37\%) of Malaysian students. But, majority of Indian students (52\%) opined to have moderate accessibility. This difference in the mode of accessibility was statistically significant $(\mathrm{p}=0.004)$ (Figure 2$)$.

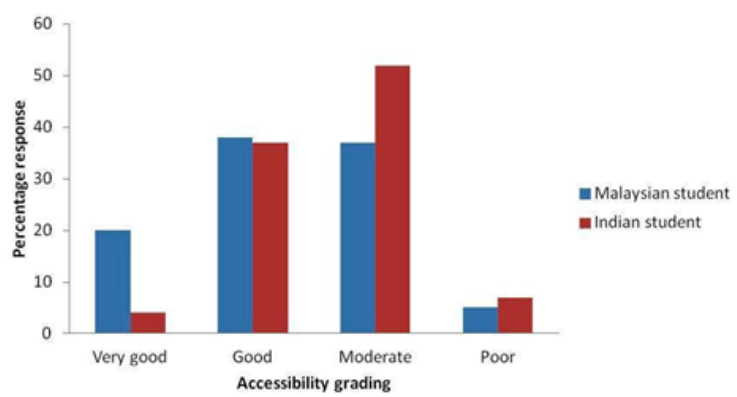

Figure 2: Comparison on accessibility towards humanity issues rated by Malaysian and Indian students.

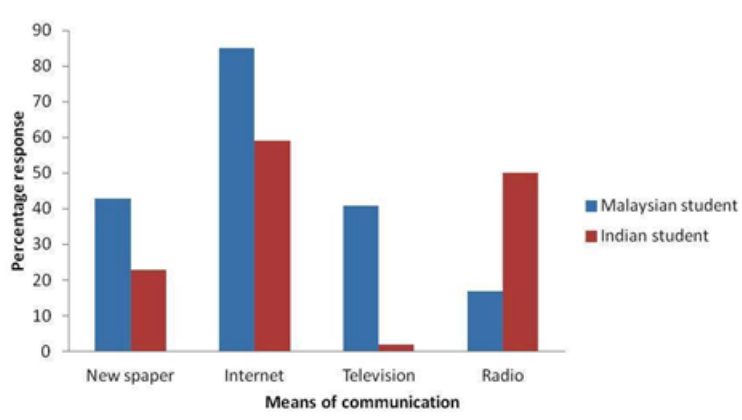

Figure 3: Profile of different means communication preferred by Malaysian and Indian students on humanitarian issues.

9. Means of communication: Proper communication is an effective tool in the measure of humanitarian related projects, social media such as internet being most popular among Malaysian (85\%) and Indian (59\%) students. The differences in the choice of means of communication among the students of two nations marked a significant differences $(\mathrm{p}<0.0001) \quad$ (Figure 3$).$ 
10. Time spending attitude of students: Time to be spent to indulge into humanitarian issues showed an equal response to all the options given in the questionnaire by the students of both nations. The majority (58\% of Malaysian and $59 \%$ Indian) of students were ready to indulge in humanitarian related issues as and when required. This difference, as expected did not show statistical significance $(\mathrm{p}=0.866)$ (Figure 4).

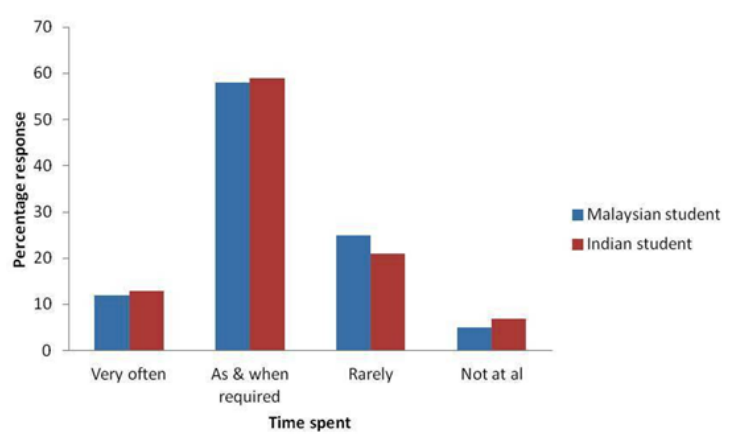

Figure 4: Graphic representation of time spent to indulge onto humanitarian issue by Malaysian and Indian students.

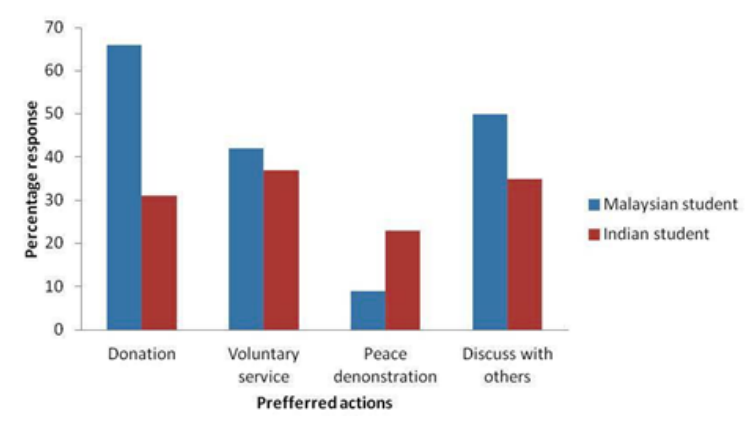

Figure 5: Profile of various actions preferred to be done by Malaysian and Indian students to get involved in humanitarian issues.

11. Choice of mode of action: Mode of action in various activities pertaining to humanitarian issues when analyzed disclosed that, majority of Malaysian students prefer offering financial support by donation $(66 \%)$ which was followed by discussing about the matters with the fellow friends and others, thus involving in an awareness campaign (50\%). Indian students prefer to work as volunteer $(37 \%)$ for the victims followed by awareness campaign (35\%). Differences in the choice of action between the students of both nations was found to be statistically significant $(\mathrm{p}=0.001)$ (Figure 5).

\section{Discussion}

Humanitarian aid is a commitment to support the victims who have experienced unexpected emergencies and who need a wider assistance to maintain their quality of life. The humanitarian orientation deserves more attention in the current reform of science education. To date, there has been negligible discussion in the literature or fast reachable social media about the awareness on humanitarian issues particularly among the young individuals (4). Necessity of humanitarian orientation is warranted in rationality with the awareness of many qualities (5).

In a review work by Janet et al, about the volunteer motivation of college student volunteers with the parameters of egoistic and altruistic motivational components and situational factors reported the more concern by the younger volunteers with the reason that are not often altruistic (6).

An investigation was performed on 40 medical students' motivations to participate in a volunteer community-based program for pregnant women's of traditionally underserved groups by assessing with a self-report instrument and was found that as compared to active adult volunteers and university students, the Medical students' motivations to participate were higher (7).

The factors affecting students' perception on humanitarian issues as tested in the current survey under the background of different parameters which could reflect different locality, diverse culture and dissimilar socio-economic status of two nations and the perspectives were evaluated in terms of student's outlook and actions on the matter of humanitarian issues are discussed as follows.

Participant's residential location status showing higher incidence of urban residency of Malaysian students than Indian students probably ( $p<0.001)$ could be one of the factors where the hypothesis on the perception of humanitarian issue with the background of area of residence might have interfered. Nevertheless, the response obtained can vary more as residential area plays 
an important role as it can determine their accessibility towards the issues.

Majority of participants of both groups involved in the current survey were found to be living in peaceful environment, while the rest live in a racist society. Political and economic stability allow the citizen to live in a peaceful environment. Similarly, practice of good values and virtue in the community help contribute to peaceful environment. In contrast, oppression, discrimination and the act of classifying people according to their caste and origin may create an unfavorable living environment.

Malaysian and Indian student's accessibility towards the humanitarian issue were somewhat between moderate and good. Malaysian student's accessibility was significantly higher $(\mathrm{p}<0.05)$ compared to Indian counterparts. This might be due to better infrastructures, facilities, and technology that Malaysian students own.

Malaysian students prefer to use internet (85\%) succeeded by newspaper $(43 \%)$ and television $(41 \%)$ as effective source of communication which could reach the mass efficiently. Indian students also prefer the usage of internet with the lesser preference (59\%) compared to Malaysian students which was followed by radio $(50 \%)$ and newspaper $(23 \%)$. Never the less, Indian student's preference on means of communication assessed to be significantly lower than Malaysian $(\mathrm{p}<0.001)$. This reflects the socio-economic status of two nations which could affect on the humanitarian issues.

The higher incidence of positive role of family members is a healthy approach in encouraging their younger ones towards humanitarian issues among both the nations. This could be probably due to the increase in awareness among the family members regarding the importance in knowing the humanitarian issues. Moreover, in this global era, it is easier for parents to provide better education to their children. This is supported by a study conducted on European Union (EU) citizens. The result has revealed over $68 \%$ of people from high level education have found EU humanitarian aids are totally justified for any victims of natural disasters or conflicts (8).

Attitude of best friend of the participant was also one of the major influential factors which could divert the perception of an individual towards positive or negative aspect. As majority of the respondent's verdict fall in favor of positive attitude in both groups, students admit that, they were benefited by their friend's interest in humanitarian issue and this indirectly influenced them.

Student attitude towards the time spent on humanitarian related issues, reveled more than $60 \%$ of students from both the nations prefer to spend their time on humanitarian issue as and when called for. However, $10 \%$ of the study group from either nation update themselves about the issue as 'very often'. The lack of incentive to probe into humanitarian issue is probably due to time constraints owing to a hectic student life Most of them may indulge into the issue only when it is needed in their study or if it is beneficial to their life.

About the student's individual interest towards any event related to humanitarian issue, majority of the students of either nation $(80 \%$ of Malaysian and $70 \%$ of Indians) with the significant difference $(\mathrm{p}<0.05)$ showed their interest towards humanitarian related issues. This remarkable response of interest in the issue may be influenced by factors such as environmental factor, parents and friends encouragement etc. In a study on humanitarian aids which has been conducted by European Union (EU), it stated that the level of education, occupation, political stance and multicultural family background affects the EU humanitarian aid perceived justification by their citizen (8). Another probability may be due to oppressed situations where individuals face in their life has made them to stand up to this humanitarian issue.

Regarding the choices of actions to get involved in the issue between Malaysian and Indian students tested, Malaysian students prefer to offer financial support (donation), volunteer involvement and discussing with their friends 
than the Indian students choices. This is may be due to the economic status of the nation, and increased number of organizations in the Malaysia, makes them to afford financial benefit to the victims of humanitarian abuse. On the other hand, majority of the Indian students prefer in joining peace demonstration over Malaysian students choice of the same because of the rich tradition and unique background of family oriented social life, which is in favor of creating the self awareness among the citizens with the involvement on peace demonstrations. The student attitude between two nations about the actions to get involved in the humanitarian issues were statistically significant $(\mathrm{p}<0.05)$.

There are not much remarkable differences between the students of both the nations on their level of knowledge about the humanitarian issues. This shows the role of humanitarian issues appreciable among the students. Overall results of present survey reflected a common fact among the students of both the nations that they are concerned about the humanitarian issues and prefer to support the necessity to be concerned with the humanitarian issue. The correlation in this aspect when compared between the students of two nations were statistically significant $(\mathrm{p}<0.05)$. This might be influenced by their background of studies and role of health professionals in such events, which is greatly appreciated. In a study done on European Union (EU), about $65 \%$ subjects have totally justified for helping victims of natural disasters or conflicts outside EU territory by providing them with humanitarian aid. Thus, this shows that majority of students regardless of their different countries of origin have agreed on the necessity of being concerned on the issue (8).

\section{Conclusion}

In conclusion, in spite of significant difference of opinions on the role of family members, mode of accessibility, effective means of communication, favorable interest and necessity with the choice of actions to indulge the issues, the major perspective has been observed as a positive and encouraging attitude towards humanitarian issue among the students of both nations. The differences in the opinions in certain aspects tested in the current study could be attributed to socio-economic status of the two countries which does influence citizen's perception for certain extent.

\section{Acknowledgement}

We would like to thank Dr. Reem Rachel Abraham, Dept. of physiology, Melaka Manipal Medical College (Manipal campus), Manipal University, Manipal- 576104 Karnataka state, India for her support to the study.

\section{Reference}

1. Leslie S, Muchael J S. Rape in war: the humanitarian response. CMAJ. 2000;163(9): 1152-1156

2. Marion B, Simon M. ABC of conflict and disaster. Humanitarian assistance: Standards, skills, training and experience. BMJ. 2005; 330(7501): 1199-1201

3. Thomas D. Fletcher, Debra A. Major1 Medical Students' Motivations to Volunteer: An Examination of the Nature of Gender Differences. Sex Roles July 2004;51(12):109-114

4. Mathew $\mathrm{R} H$. Interpretive description: Reflections arising from a study of the moral experience of health professionals in humanitarian work. Qual Health Res, 2009. 19(9): 1284-1292

5. Liu De-hua. On the Humanitarian value of science education. Journal of Jiaying University. 2000-01. Accessed on $24^{\text {th }}$ January 2014: http://en.cnki.com.cn/Article_en/CJFDTOT AL-JYDB200001014.htm

6. Janet C W, Stanley CD, Clint G. Motivations of College student volunteers: A Review. Journal of Student affairs Research and Practice. 1997;34(2):135-147

7. Carrie L. Switzera, Galen E. Switzera, Arthur A. Stukasa, Carol E. Medical Student Motivations to Volunteer: Gender Differences and Comparisons to Other Volunteers. Bakera Journal of Prevention \& Intervention in the Community. 1999;18:(12):53-64

8. European Commission: Humanitarian aid. 2006. Accessed on $24^{\text {th }}$ January 2014: http://ec.europa.eu/echo/files/policies/consen sus/eurobarometer_en.pdf 